high-dose bolus interleukin-2 for patients with high-risk renal cell carcinoma: a cytokine working group randomised trial. J Clin Oncol 21: $3133-3140$

Dencausse Y, Hartung G, Sturm J, Kopp-Schneider A, Hagmuller E, Wojatschek C, Lindemann H, Fritze D, Queisser W (2002) Adjuvant chemotherapy in stage III colon cancer with 5-fluorouracil and levamisole versus 5-fluorouracil and leucovorin. Onkologie 25: 426-430 Douillard JY, Hoff PM, Skillings JR, Eisenberg P, Davidson N, Harper P, Vincent MD, Lembersky BC, Thompson S, Maniero A, Benner SE (2002) Multicenter phase III study of uracil/tegafur and oral leucovorin versus fluorouracil and leucovorin in patients with previously untreated metastatic colorectal cancer. J Clin Oncol 20: 3605-3616

Ito K, Nakazato H, Koike A, Takagi H, Saji S, Baba S, Mai M, Sakamoto J, Ohashi Y (2004) Long-term effect of 5-fluorouracil enhanced by intermittent administration of polysaccharide $\mathrm{K}$ after curative resection of colon cancer. A randomized controlled trial for 7-year follow-up. Int J Colorectal Dis 19: $157-164$

Kudo S, Tanaka J, Kashida H, Tamegai Y, Endo S, Yamano HO (2002) Effectiveness of immunochemotherapy with PSK, a protein-bound polysaccharide, in colorectal cancer and changes of tumor marker. Oncol Rep 9: 635-638
Messing EM, Manola J, Wilding G, Propert K, Fleischman J, Crawford ED, Pontes JE, Hahn R, Trump D (2003) Phase III study of interferon alfa-NL as adjuvant treatment for respectable renal cell carcinoma: an Eastern Cooperative Oncology Group/Intergroup trial. J Clin Oncol 21: $1214-1222$

Ohwada S, Ikeya T, Yokomori T, Kusaba T, Roppongi T, Takahashi T, Nakamura S, Kakinuma S, Iwazaki S, Ishikawa H, Kawate S, Nakajima T, Morishita Y (2004) Adjuvant immunochemotherapy with oral Tegafur/ Uracil plus PSK in patients with stage II or III colorectal cancer. $\mathrm{Br} J$ Cancer 90: $1003-1010$

QUASAR Collaborative Group (2000) Comparison of fluorouracil with additional levamisole, higher-dose folinic acid, or both, as adjuvant chemotherapy for colorectal cancer: a randomised trial. Lancet 355: $1588-1596$

Sabel MS, Sondak VK (2003) Pros and cons of adjuvant interferon in the treatment of melanoma. Oncologist 8: 451-458

Yamaguchi K, Takagi Y, Aoki S, Futamura M, Saji S (2000) Significant detection of circulating cancer cells in the blood by reverse transcriptase-polymerase chain reaction during colorectal cancer resection. Ann Surg 232: $58-65$

\title{
Reply: Adjuvant immunochemotherapy with oral Tegafur/Uracil plus PSK in patients with stage II or III colorectal cancer
}

\author{
S Ohwada*,I and Y Morishita' \\ 'Department of Surgery, Gunma University Graduate School of Medicine, 3-39-15, Showa-Machi, Maebashi, Gunma 37 I-85 I I, Japan
}

British Journal of Cancer (2004) 91, I22I-1223. doi:I0.1038/sj.bjc.6602101 www.bjcancer.com

Published online 10 August 2004

(c) 2004 Cancer Research UK

Sir,

We thank Dr C Alliot for his comments and critique in the editorial accompanying our article (Ohwada et al, 2004). Regarding the choice of the control arm, we agree that the standard adjuvant treatment for stage III colon cancer since 1990 has been 5fluorouracil plus leucovorin (5-FU/LV) (NIH, 1990; IMPACT, 1995; Wolmark et al, 1999). Now, FOLFOX has become a standard regimen for stage II or III colorectal cancer (Andre et al, 2004). Nevertheless, the Ministry of Health and Welfare of Japan did not approve LV for colorectal cancer until June 16, 1999. This study was conducted between October 1994 and March 1997, 2 years before official permission. Therefore, LV was unavailable as a randomised control. As you indicated, there is currently no evidence that UFT is superior to the standard regimen, even when modulated by LV. In a large phase III trial that compared UFT/LV with 5-FU/LV for untreated metastatic colorectal cancer, UFT/LV was found to be a safer, more convenient oral alternative to a standard bolus IV 5-FU/LV regimen, while producing equivalent survival; however, it was associated with an inferior time to disease progression and $22 \%$ increase in the risk of disease progression (Douillard et al, 2002). Recently, the efficacy of UFT has been

*Correspondence: Dr S Ohwada; E-mail: sohwada@med.gunma-u.ac.jp Published online 10 August 2004 determined. In randomised, controlled trials, adjuvant chemotherapy with UFT alone improved the survival of patients with completely resected pathological stage III rectal cancer (Akatsu et $a l, 2004)$ and stage I adenocarcinoma of the lung (Kato et al, 2004), compared with surgery alone.

Dr Alliot was concerned with the high proportion of patients with rectal cancer in the control arm, the impact of the quality of surgery, and the fact that no preoperative radiotherapy was administered. The 5-year disease-free survival for rectal cancer was 69.4\% (95\% CI: $56.5-82.3 \%$ ) with PSK and 52.9\% (95\% CI: $36.2-$ $69.7 \%)$ in the controls $(P=0.133)$. The difference was not significant, but the high proportion of patients with rectal cancer in the control arm may have pushed the survival for all the patients downward. Therefore, we reanalysed the 5-year disease-free survival adjusted for histologic type and tumour location and found that the survival remained significantly better for the PSK group (stratified logrank; $P=0.031$ ). The result suggests that the high proportion of patients with rectal cancer did not affect the survival significantly.

As Dr Alliot indicated, the quality of surgery is an important point when conducting any randomised, controlled trial in a surgical field. The recognition that tumour cell involvement in the circumferential margin is important in local recurrence has led to the general use of total mesorectal excision (MacFarlane et al, 
1993; Kapiteijn et al, 2001), in which the entire mesorectum is enveloped and resected using a precise, sharp dissection. Therefore, suitably qualified chief surgeons were trained in the Second Department of Surgery, Gunma University Hospital, in order to standardise surgical quality. We applied total mesorectal resection for $\mathrm{Rb}$ or Rab tumours, and tumour-specific mesorectal resection for $\mathrm{Ra}$ tumours (at least $4 \mathrm{~cm}$ of the anal mesorectum was dissected). Lateral node dissection was performed, while groin dissection was not added. In our study of rectal cancer, the rate of local recurrence was $4.8 \%$ in all patients, $2.9 \%$ in the control, and $6.1 \%$ in the PSK group. The low rate of local recurrence in our study with no preoperative radiation therapy ( $4.8 \%$ at 5 years) is similar to the excellent results achieved using preoperative radiation therapy and standard resection (Kapiteijn et al, 2001).

Oncologists agree that an early start for chemotherapy is rationally correct, because surgery provokes the circulation of neoplastic cells (Yamaguchi et al, 2000), angiogenesis, and, potentially, the development of micrometastasis, as $\mathrm{Dr}$ Alliot indicated. In his editorial, Dr Alliot does not focus on the superior results in the PSK arm, but emphasises the poor results in the control arm. The benefits of an early start for chemotherapy are supported by the significantly superior disease-free survival in the PSK arm. The survival of UFT/MMC in pathologic stage III patients was poor and was similar to that of untreated controls in standard regimens (Francini et al, 1994; IMPACT, 1995). This may be explained by the difference in the dose intensity of UFT. The UFT doses used in positive randomised trials include $600 \mathrm{mg}$ body day ${ }^{-1}$ (Malik et al, 1990), 300 or $350 \mathrm{mg} \mathrm{m}^{-2}$ day $^{-1}$ with LV (Douillard et al, 2002), $400 \mathrm{mg} \mathrm{m}^{-2}$ for 5 of 7 days (Akatsu et al, 2004), and $250 \mathrm{mg} \mathrm{m}^{-2} \mathrm{day}^{-1}$ (Kato et al, 2004), which are all higher than the $300 \mathrm{mg}$ body $^{-1}$ used in our study, despite the lack of LV modulation. The development of more effective agents or regimens should prove that an early start with chemotherapy benefits disease-free survival.

Invoking recently published data from randomised, controlled trials, the survival with PSK/UFT treatment is comparable or superior to standard 5-FU/LV regimens. The 5-year disease-free and overall survival rates were 73.0 and $81.8 \%$ for the PSK group, respectively, while the best 5 -year disease-free and overall survival rates were 65 and 76\%, respectively, in NASBP C-04 (Wolmark et al, 1999), and 63 and 70\%, respectively, in Intergroup-0089-4651 (O'Connell et al, 1998). When limited to stage III patients, the 4year disease-free and overall survival rates were 69.1 and $78.2 \%$ in the PSK group vs 65.3-72.8\% for the latter (Porschen et al, 2001). Further, in the MOSAIC trial (Andre et al, 2004), the 3-year disease-free survival rates of stage II or III patients were $72.9 \%$ for 5FM/LV and $78.2 \%$ for FOLFOX, while we achieved $77.8 \%$ for PSK/ UFT. When limited to stage III, the 3-year disease-free survival rates were $65.3 \%$ for $5 \mathrm{FM} / \mathrm{LV}$ and $72.2 \%$ for FOLFOX, while we obtained $70.9 \%$ for PSK/UFT.

I agree that disease-free survival is more meaningful than overall survival, at least in the case of adjuvant chemotherapy for colorectal cancer (Elfenbein, 2003; Andre et al, 2004); second-line therapies for recurrence, including chemotherapy and salvage surgery, can prolong the survival of colorectal cancer patients (de Gramont et al, 2000; Saltz et al, 2000; Choti et al, 2002).

There is no consensus on the optimal duration for adjuvant chemotherapy after colorectal cancer. Currently, a standard adjuvant treatment for stage III colon cancer, is 5-FU/LV for 612 months (Francini et al, 1994; O'Connell et al, 1998; IMPACTB2, 1999; Wolmark et al, 1999; QUASAR, 2000; Andre et al, 2004). Recurrences generally occur within 2 years after surgery. Indeed, in our study, $71 \%$ of cancers recurred during the first 2 years after surgery, and $85 \%$ recurred within $2 \frac{1}{2}$ years. The mean time to recurrence was $1.9 \pm 1.4$ years in the PSK group and $1.6 \pm 1.1$ years in the control group $(P=0.585)$. Porschen et al (2001) reported that the median time to relapse was 15 months with 5FU/LV treatment and 12 months with 5FU/levamisole treatment. Fluorouracil is a time-dependent agent, and a daily regimen of UFT is an effective way to maintain the blood fluorouracil level. Therefore, the daily, long-term administration of UFT may be beneficial. In addition, oral use of adjuvant chemotherapy with PSK and UFT is less toxic and less complex, as it avoids frequent treatment-related visits and thereby allows patients to receive long-term treatment.

PSK has a wide range of biological activity, remarkable immuneenhancing activity, and a broad antineoplastic scope (Wasser, 2002). Therefore, therapy with PSK differs from therapy with cytokines, such as interferon (IFN) and interleukin (IL)-2. PSK activates NK cells independent of IFN and the IL-2/IL-2 receptor system, and activates lymphokine-activated killer (LAK) cells (Ebina and Murata, 1992; Algarra et al, 1997; Harada et al, 1997; Pedrinaci et al, 1999; Garcia-Lora et al, 2001; Garcia-Lora et al, 2003). PSK also functions as a specific biochemical modulator of antitumour agents, such as mitomycin C, 5-fluorouracil, cyclophosphamide, bleomycin, CPT-11, cisplatin, and docetaxel (Zhang et al, 2003). PSK upregulates the IL-1, IL-6, and IL-8 genes in peripheral mononuclear cells (Hirose et al, 1990), as well as the genes for TNF and macrophage chemotactic factors in tumour cells (Ebina and Murata, 1992), and induces apoptosis (Yefenof et al, 1995; Zhang et al, 2003). In addition, PSK induces differentiationrelated genes and produces leukemic cell differentiation in vitro (Yefenof et al, 1995). Furthermore, PSK suppresses tumour cell invasiveness via the downregulation of several invasion-related factors, which include TGF- $\beta_{1}$, urokinase plasminogen activator, and the matrix metalloproteinase (MMP)-2 and -9 (Zhang et al, 2000). These activities of PSK are varied and differ from those of levamisole. Although the efficacy of levamisole in a randomised, controlled trial was questionable (QUASAR, 2000), the results for levamisole did not represent those for PSK.

Finally, I thank Dr C Alliot for his comments again. This study shows that PSK is a good candidate for convenient therapy with less toxicity, better compliance, and comparable survival to FOLFOX or 5FU/LV regimens, although our results are not definitive.

\section{REFERENCES}

Akatsu T, Moirya S, Yoshida S, Shirao K, Ohashi Y, Kodaira S (2004) Adjuvant oral uracil and tegafur (UFT) improves survival after complete mesorectal excision (ME) of pathologic TNM stage III rectal cancer. In Proc Am Soc Clin Oncol, Vol. 23, pp 251, New Orleans

Algarra I, Collado A, Garrido F (1997) Protein bound polysaccharide PSK abrogates more efficiently experimental metastases derived from $\mathrm{H}-2$ negative than from $\mathrm{H}-2$ positive fibrosarcoma tumor clones. J Exp Clin Cancer Res 16: $373-380$

Andre T, Boni C, Mounedji-Boudiaf L, Navarro M, Tabernero J, Hickish T, Topham C, Zaninelli M, Clingan P, Bridgewater J, Tabah-Fisch I, de Gramont A (2004) Oxaliplatin, fluorouracil, and leucovorin as adjuvant treatment for colon cancer. N Engl J Med 350: 2343-2351

Choti MA, Sitzmann JV, Tiburi MF, Sumetchotimetha W, Rangsin R, Schulick RD, Lillemoe KD, Yeo CJ, Cameron JL (2002) Trends in longterm survival following liver resection for hepatic colorectal metastases. Ann Surg 235: $759-766$

de Gramont A, Figer A, Seymour M, Homerin M, Hmissi A, Cassidy J, Boni C, Cortes-Funes H, Cervantes A, Freyer G, Papamichael D, Le Bail N, Louvet C, Hendler D, de Braud F, Wilson C, Morvan F, Bonetti A (2000) Leucovorin and fluorouracil with or without oxaliplatin as first-line treatment in advanced colorectal cancer. J Clin Oncol 18: 2938-2947

Douillard JY, Hoff PM, Skillings JR, Eisenberg P, Davidson N, Harper P, Vincent MD, Lembersky BC, Thompson S, Maniero A, Benner SE (2002) Multicenter phase III study of uracil/tegafur and oral leucovorin vs 
fluorouracil and leucovorin in patients with previously untreated metastatic colorectal cancer. J Clin Oncol 20: 3605-3616

Ebina T, Murata K (1992) Antitumor effect of PSK at a distant site: tumorspecific immunity and combination with other chemotherapeutic agents. Jpn J Cancer Res 83: 775-782

Elfenbein GJ (2003) Stem-cell transplantation for high-risk breast cancer. $N$ Engl J Med 349: 80-82

Francini G, Petrioli R, Lorenzini L, Mancini S, Armenio S, Tanzini G, Marsili S, Aquino A, Marzocca G, Civitelli S, Mariani L, De Sando D, Bovenga S, Lorenzi M (1994) Folinic acid and 5-fluorouracil as adjuvant chemotherapy in colon cancer. Gastroenterology 106: 899-906

Garcia-Lora A, Martinez M, Pedrinaci S, Garrido F (2003) Different regulation of PKC isoenzymes and MAPK by PSK and IL-2 in the proliferative and cytotoxic activities of the NKL human natural killer cell line. Cancer Immunol Immunother 52: 59-64

Garcia-Lora A, Pedrinaci S, Garrido F (2001) Protein-bound polysaccharide $\mathrm{K}$ and interleukin-2 regulate different nuclear transcription factors in the NKL human natural killer cell line. Cancer Immunol Immunother 50: $191-198$

Harada M, Matsunaga K, Oguchi Y, Iijima H, Tamada K, Abe K, Takenoyama M, Ito O, Kimura G, Nomoto K (1997) Oral administration of PSK can improve the impaired anti-tumor CD4+ T- cell response in gut-associated lymphoid tissue (GALT) of specific- pathogen-free mice. Int J Cancer 70: $362-372$

Hirose K, Zachariae COC, Oppenheim JJ, Matsushima K (1990) Induction of gene expression and production of immunomodulating cytokines by PSK in human peripheral blood mononuclear cells. Lymphokine Res 4: $475-483$

IMPACT (1995) Efficacy of adjuvant fluorouracil and folinic acid in colon cancer. International Multicentre Pooled Analysis of Colon Cancer Trials (IMPACT) investigators. Lancet 345: 939-944

IMPACTB2 (1999) Efficacy of adjuvant fluorouracil and folinic acid in B2 colon cancer. International Multicentre Pooled Analysis of B2 Colon Cancer Trials (IMPACT B2) Investigators. J Clin Oncol 17: $1356-1363$

Kapiteijn E, Marijnen CA, Nagtegaal ID, Putter H, Steup WH, Wiggers T, Rutten HJ, Pahlman L, Glimelius B, van Krieken JH, Leer JW, van de Velde CJ (2001) Preoperative radiotherapy combined with total mesorectal excision for resectable rectal cancer. $N$ Engl J Med 345: $638-646$

Kato H, Ichinose Y, Ohta M, Hata E, Tsubota N, Tada H, Watanabe Y, Wada H, Tsuboi M, Hamajima N (2004) A randomized trial of adjuvant chemotherapy with uracil-tegafur for adenocarcinoma of the lung. $N$ Engl J Med 350: 1713-1721

MacFarlane JK, Ryall RD, Heald RJ (1993) Mesorectal excision for rectal cancer. Lancet 341: 457-460

Malik ST, Talbot D, Clarke PI, Osborne R, Reznek R, Wrigley PF, Slevin ML (1990) Phase II trial of UFT in advanced colorectal and gastric cancer. $\mathrm{Br}$ J Cancer 62: $1023-1025$

NIH (1990) Adjuvant therapy for patients with colon and rectal cancer. JAMA 264: $1444-1450$
O'Connell MJ, Laurie JA, Kahn M, Fitzgibbons Jr RJ, Erlichman C, Shepherd L, Moertel CG, Kocha WI, Pazdur R, Wieand HS, Rubin J, Vukov AM, Donohue JH, Krook JE, Figueredo A (1998) Prospectively randomized trial of postoperative adjuvant chemotherapy in patients with high-risk colon cancer. J Clin Oncol 16: 295-300

Ohwada S, Ikeya T, Yokomori T, Kusaba T, Roppongi T, Takahashi T, Nakamura S, Kakinuma S, Iwazaki S, Ishikawa H, Kawate S, Nakajima T, Morishita Y (2004) Adjuvant immunochemotherapy with oral Tegafur/ Uracil plus PSK in patients with stage II or III colorectal cancer: a randomised controlled study. Br J Cancer 90: 1003-1010

Pedrinaci S, Algarra I, Garrido F (1999) Protein-bound polysaccharide (PSK) induces cytotoxic activity in the NKL human natural killer cell line. Int J Clin Lab Res 29: 135-140

Porschen R, Bermann A, Loffler T, Haack G, Rettig K, Anger Y, Strohmeyer G (2001) Fluorouracil plus leucovorin as effective adjuvant chemotherapy in curatively resected stage III colon cancer: results of the trial adjCCA- 01. J Clin Oncol 19: 1787-1794

QUASAR (2000) Comparison of fluorouracil with additional levamisole, higher-dose folinic acid, or both, as adjuvant chemotherapy for colorectal cancer: a randomised trial. QUASAR Collaborative Group. Lancet 355: $1588-1596$

Saltz LB, Cox JV, Blanke C, Rosen LS, Fehrenbacher L, Moore MJ, Maroun JA, Ackland SP, Locker PK, Pirotta N, Elfring GL, Miller LL (2000) Irinotecan plus fluorouracil and leucovorin for metastatic colorectal cancer. Irinotecan Study Group. N Engl J Med 343: $905-914$

Wasser SP (2002) Medicinal mushrooms as a source of antitumor and immunomodulating polysaccharides. Appl Microbiol Biotechnol 60: $258-274$

Wolmark N, Rockette H, Mamounas E, Jones J, Wieand S, Wickerham DL, Bear HD, Atkins JN, Dimitrov NV, Glass AG, Fisher ER, Fisher B (1999) Clinical trial to assess the relative efficacy of fluorouracil and leucovorin, fluorouracil and levamisole, and fluorouracil, leucovorin, and levamisole in patients with Dukes' B and C carcinoma of the colon: results from National Surgical Adjuvant Breast and Bowel Project C-04. J Clin Oncol 17: $3553-3559$

Yamaguchi K, Takagi Y, Aoki S, Futamura M, Saji S (2000) Significant detection of circulating cancer cells in the blood by reverse transcriptasepolymerase chain reaction during colorectal cancer resection. Ann Surg 232: $58-65$

Yefenof E, Gafanovitch I, Oron E, Bar M, Klein E (1995) Prophylactic intervention in radiation-leukemia-virus-induced murine lymphoma by the biological response modifier polysaccharide K. Cancer Immunol Immunother 41: 389-396

Zhang H, Morisaki T, Matsunaga H, Sato N, Uchiyama A, Hashizume K, Nagumo F, Tadano J, Katano M (2000) Protein-bound polysaccharide PSK inhibits tumor invasiveness by down- regulation of TGF-betal and MMPs. Clin Exp Metastasis 18: 343-352

Zhang H, Morisaki T, Nakahara C, Matsunaga H, Sato N, Nagumo F, Tadano J, Katano M (2003) PSK-mediated NF-kB inhibition augments docetaxel-induced apoptosis in human pancreatic cancer cells NOR-P1. Oncogene 22: 2088-2096 